\title{
Outcome after osteosynthesis of hip fractures in nonagenarians
}

\author{
This article was published in the following Dove Press journal: \\ Clinical Interventions in Aging \\ 17 December 2013 \\ Number of times this article has been viewed
}

\author{
Kevin de Leur' \\ Jos P A M Vroemen' \\ Dagmar I Vos' \\ Leon Elmans ${ }^{2}$ \\ Lijckle van der Laan' \\ 'Department of Surgery, \\ ${ }^{2}$ Orthopedics, Amphia Hospital, \\ Breda, The Netherlands
}

Correspondence: Kevin de Leur Department of Surgery, Amphia Hospital, Molengracht $21, \mathrm{NL}-4818 \mathrm{CK}$

Breda, The Netherlands

Tel +3I 0765953008

Fax +310765953818

Email kevin_de_leur@hotmail.com
Background: Hip fractures in the elderly population are associated with high morbidity and mortality. However, there is still a lack of information on mortality and loss of independence in extremely elderly people with a hip fracture.

Objective: To study functional outcomes and mortality after osteosynthesis of hip fractures in very old patients in our clinic.

Patients and methods: Hospital charts of all patients over 90 years old who were operated for a hip fracture between January 2007 and December 2011 were reviewed. Outcome measures were mortality, preoperative and postoperative mobility, and loss of independence.

Results: A total of 149 patients were included; 132 (89\%) women, median age 93.5 \pm 2.45 years. Thirty-six (24\%) patients were classified as American Society of Anesthesiologists (ASA) grade 2, $104(70 \%)$ as ASA grade 3, and nine (6\%) as ASA grade 4. The Charlson comorbidity index (CCI) score was 2 or less in $115(77 \%)$ patients and $34(23 \%)$ patients scored 3 or more points. Short-term survival was $91 \%$ and $77 \%$ at 30 days and 3 months, respectively. Long-term survival was $64 \%, 42 \%$, and $18 \%$ at 1,3 , and 5 years after surgery, respectively. Survival was significantly better in patients with lower ASA scores $(P=0.005)$. No significant difference in survival was measured between patients according to CCI score $(P=0.13)$. Fifty-one percent of patients had to be accommodated in an institution with more care following treatment, and $57 \%$ were less mobile after osteosynthesis of a hip fracture.

Conclusion: Our study shows that short-term mortality rates in very elderly patients with a hip fracture are high and there is no clear predictive value for mortality. ASA classification is the best predictive value for overall mortality. A large proportion of these patients lost their independence after osteosynthesis of a hip fracture.

Keywords: hip fracture, osteosynthesis, very elderly people, mortality, loss of independence

\section{Introduction}

Proximal femoral fractures are an important cause of hospitalization of elderly people, currently leading to nearly half of all injury-related health care costs of aged adults in The Netherlands. ${ }^{1}$ Most hip fractures $(80 \%)$ occur in persons aged 65 years and older. ${ }^{2,3}$ This population is increasing rapidly worldwide. ${ }^{4}$ The overall 1 -year mortality rate associated with hip fracture is reported to be between $14 \%$ to $47 \%$. ${ }^{5,6}$ Still, there is missing data on functional outcomes and mortality rates in extremely elderly patients. ${ }^{7}$

Demographic aging is caused by decreased fecundity along with increased life expectancy. Consequently, age-related problems are rising, including osteoporosis and falls. ${ }^{1,8}$ Falls are the main cause of injury among elderly people; one-third of the population over 65 years fall on average once a year, leading to a high health care demand., ${ }^{9,10}$ 
The majority of fall-related injuries that require treatment in a hospital are fractures (60\%) and superficial injuries (21\%). ${ }^{11}$ Older individuals in particular are at an increased risk of sustaining fractures due to underlying medical conditions, especially osteoporosis. ${ }^{12,13}$ Typical osteoporotic fractures include those of the hip, wrist, vertebrae, and upper arm. ${ }^{14}$

Hip fractures, more than any other type of fracture, are associated with loss of independence, morbidity, and mortality, and have a major impact on the quality of life of the patients and their caregivers. ${ }^{5,15-17}$ The care for these patients is complex and requires a multidisciplinary and multiagency input. ${ }^{5}$

Despite the increasing population of extremely old patients with hip fractures, data on mortality rates, predictive values of risk factors on mortality, and functional outcomes after osteosynthesis of hip fractures in this population is still lacking. The aim of our study was to evaluate outcomes after osteosynthesis of hip fractures in a population of extremely old patients aged over 90 years.

\section{Patients and methods Study design}

Patients aged 90 years and older presenting with a fracture of the hip were identified retrospectively from January 2007 until December 2011. All patients undergoing osteosynthesis of a hip fracture were included. Data from patient records were collected in a database containing the following parameters: type of hip fracture, comorbidity scores, type of intervention, time until intervention, age, clinical outcome, and survival. The type of hip fracture was scored according to the Müller AO classification of fractures. Comorbidity was assessed by the Charlson comorbidity index (CCI). ${ }^{18}$ The CCI determines comorbidity level on the basis of the number and severity of 19 predefined conditions. It provides a weighted score of comorbidities, which can be used to predict short- and long-term outcomes such as function, length of hospital stay, and mortality rates. The CCI is the most widely used scoring system for comorbidity used by researchers and clinicians. ${ }^{18}$ The age-adjusted variant of the CCI was not used, because our study population contained only patients aged over 90 years. The preoperative condition of patients was also scored according to the American Society of Anesthesiologists (ASA) grading scale. ${ }^{19}$ The ASA physical status classification system is a system for assessing the fitness of cases before surgery. The ASA adopted the five-category physical status classification system; the categories are: 1) healthy person; 2) mild systemic disease; 3) severe systemic disease; 4) severe systemic disease that is a constant threat to life; and 5) a moribund person who is not expected to survive without the operation. Interventions were osteosynthesis of a hip fracture with a Gamma nail (Stryker Corporation, Kalamazoo, MI, USA), dynamic hip screw (DHS), or cannulated screws. Furthermore, the total preoperative delay (time between fracture and surgery), and preoperative hospitalization delay (time between admission and surgery) were calculated. Development of postoperative delirium was measured using hospital records. Delirium was diagnosed using the Delirium Observation Screening (DOS) scale. Outcome was measured in terms of mortality, morbidity, and loss of independence. The consequence in terms of loss of independence was scored according to change in place of residence and/or mobility. We contacted patients' general practitioner and/or place of residence to assess these variables. In The Netherlands, a nursing home is a place where elderly people who can't live independently anymore receive help with household tasks, personal care, and meals. A care home is a place where people receive medical care after hospital stay or in case of prolonged illness. We also assessed predictive values of risk factors on mortality rates. We calculated mortality at 30 days, 3 months, 1 year, 3 years, and 5 years after intervention. Follow-up data were obtained from hospital records. If mortality was not reported, the general practitioner was contacted by the authors to determine survival.

\section{Surgery}

Patients were treated by a general or orthopedic surgeon. The type of hip fracture was evaluated by standard X-ray examination of the pelvis and broken hip. The type of osteosynthesis was determined at the discretion of the treating physician. Preoperatively, patients underwent cardiopulmonary and medical evaluation to estimate operative risk in order to optimize their general physical status if necessary. After surgery, mobilization and weight bearing was allowed as soon as possible according to the surgeon's advice. Patients started to mobilize under the supervision of the physiotherapist.

\section{Ethics approval}

We consulted the institutional review board (Advisory commission involving Human Subjects Research Amphia Hospital - AMOA) of the Amphia hospital and they confirmed that no formal written waiver for ethics approval was required, because of the retrospective design of the study. Also there was no written consent needed from the patients.

\section{Statistical analysis}

SPSS 19.0 for Windows (IBM Corporation, Armonk, NY, USA) was used for the statistical analysis. Frequencies and 
descriptive statistics were used for reporting the baseline characteristics of the patient group. The chi-square test was used to determine statistical significance.

In univariate analysis, survival probabilities were calculated using the Kaplan-Meier method. The log-rank test was used to determine statistical significance of the categorical variable at hand. Multivariate survival analyses were performed using the Cox proportional hazards model. A $P$-value below 0.05 was considered to denote statistical significance.

\section{Results}

In total 149 patients were included; 132 (89\%) were women and the median age was $93.5 \pm 2.45$ years. Preoperatively, 36 (24\%) patients were classified as ASA grade 2, 104 (70\%) as ASA grade 3, and nine (6\%) as ASA grade 4 according to the ASA classification. The CCI score was 2 or less in 115 (77\%) patients and 34 (23\%) patients scored 3 or more points, which means a higher level of comorbidity preoperatively (Table 1). The types of hip fractures according to different fracture classifications are listed in Table 2. Total follow-up ranged from less than 1 month to 70 months (mean 23 months), during which 99 deaths were observed.

After osteosynthesis the overall survival was $91 \%$ and $77 \%$ at 30 days and 3 months, respectively. Long-term survival was $64 \%, 42 \%$, and $18 \%$ at 1,3 , and 5 years after surgery (Figure 1). When patients were divided according to ASA classification, overall survival was significantly better in patients with an ASA score of 2 compared to patients with an ASA score of 3 or $4(P=0.005$, Figure 2$)$. No significant difference in survival was measured between patients with a CCI score of 2 or less and patients with a CCI score of 3 or more ( $P=0.13$, Figure 3 ). Mortality rates in relation to type of anesthesia (general or spinal) were

Table I Baseline characteristics of 149 patients with hip fractures

\begin{tabular}{ll}
\hline Gender (\%) & \\
Men & $17(1 \mathrm{I} .4)$ \\
Women & $132(88.6)$ \\
Age (years) \pm SD & $93.5 \pm 2.45$ \\
Charlson comorbidity index score (\%) & \\
0 & $35(23.5)$ \\
I & $52(34.9)$ \\
2 & $28(18.8)$ \\
3 & $20(13.4)$ \\
$\geq 4$ & $14(9.4)$ \\
ASA classification (\%) & \\
2 & $36(24.2)$ \\
3 & $104(69.8)$ \\
4 & $9(6.0)$ \\
\hline Abbreviations: ASA, American Society of Anesthesiologists; SD, standard deviation.
\end{tabular}

Table 2 Type of fracture according to different fracture classifications

\begin{tabular}{|c|c|c|c|}
\hline & $\begin{array}{l}\text { Intracapsular } \\
(n=16)\end{array}$ & $\begin{array}{l}\text { Pertrochanteric } \\
(n=I \mid 2)\end{array}$ & $\begin{array}{l}\text { Subtrochanteric } \\
(n=2 I)\end{array}$ \\
\hline \multicolumn{4}{|c|}{ AO classification } \\
\hline $\mathrm{Al}$ & & 40 & \\
\hline $\mathrm{A} 2$ & & 65 & \\
\hline $\mathrm{A} 3$ & & 7 & 21 \\
\hline $\mathrm{BI}$ & 7 & & \\
\hline B2 & 7 & & \\
\hline B3 & 2 & & \\
\hline \multicolumn{4}{|c|}{ Evans classification } \\
\hline Type I & & 13 & \\
\hline Type 2 & & 21 & \\
\hline Type 3 & & 13 & \\
\hline Type 4 & & 34 & \\
\hline Type 5 & & 31 & \\
\hline Reversed & & & 21 \\
\hline type & & & \\
\hline \multicolumn{4}{|c|}{ Pauwels classification } \\
\hline Type I & 2 & & \\
\hline Type 2 & 7 & & \\
\hline Type 3 & 7 & & \\
\hline \multicolumn{4}{|c|}{ Garden classification } \\
\hline Type I & 5 & & \\
\hline Type 2 & 3 & & \\
\hline Type 3 & 6 & & \\
\hline Type 4 & 2 & & \\
\hline
\end{tabular}

not significantly different $(P=0.82$, Figure 4$)$. There was no significant difference in mortality rates between patients operated within 24 hours of the occurrence of hip fracture $(\mathrm{N}=96)$ and patients operated on after 24 hours $(\mathrm{N}=53)$ $(P=0.62$, Figure 5$)$. Mortality rates were not significantly different between patients with and without postoperative delirium $(P=0.37)$, nor between males and females $(P=0.84)$. Fully independent patients had a significantly lower mortality rate $(P=0.011)$. The contribution of all of these variables simultaneously, now also including the continuous variables of age and length of hospital stay, to the Cox proportional hazards model was significant $(P<0.0005)$; the significant variables being ASA score, full independence, length of hospital stay, and age. The mortality rate ratio of ASA score 3 or 4 relatively to ASA score 2 was $1.9(P=0.017 ; 95 \%$ confidence interval [CI]: 1.1-3.3). Fully independent patients had a lower mortality rate than dependent patients (mortality rate ratio $=0.60$; $P=0.027$; 95\% CI: $0.38-0.94)$. A 1 -year increase in age resulted in a mortality rate ratio of $1.16(P=0.001 ; 95 \% \mathrm{CI}$ : 1.06-1.26). A 1-day increase in hospital stay resulted in a mortality rate ratio of 1.03 ( $P=0.019 ; 95 \%$ CI: $1.01-1.05)$. The $P$-values of the other variables in the model ranged from 0.36 to 0.73 . 


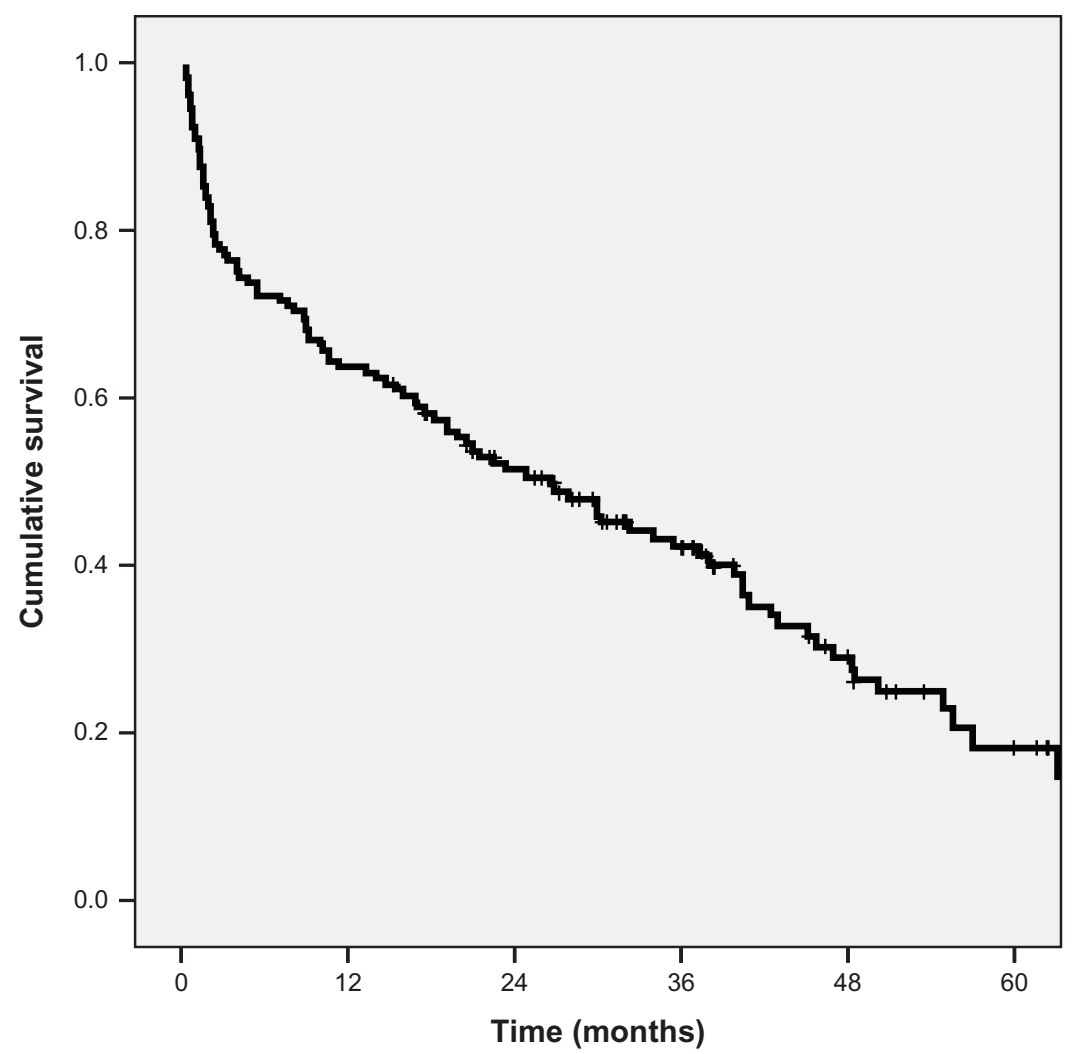

Figure I Overall survival of all patients.

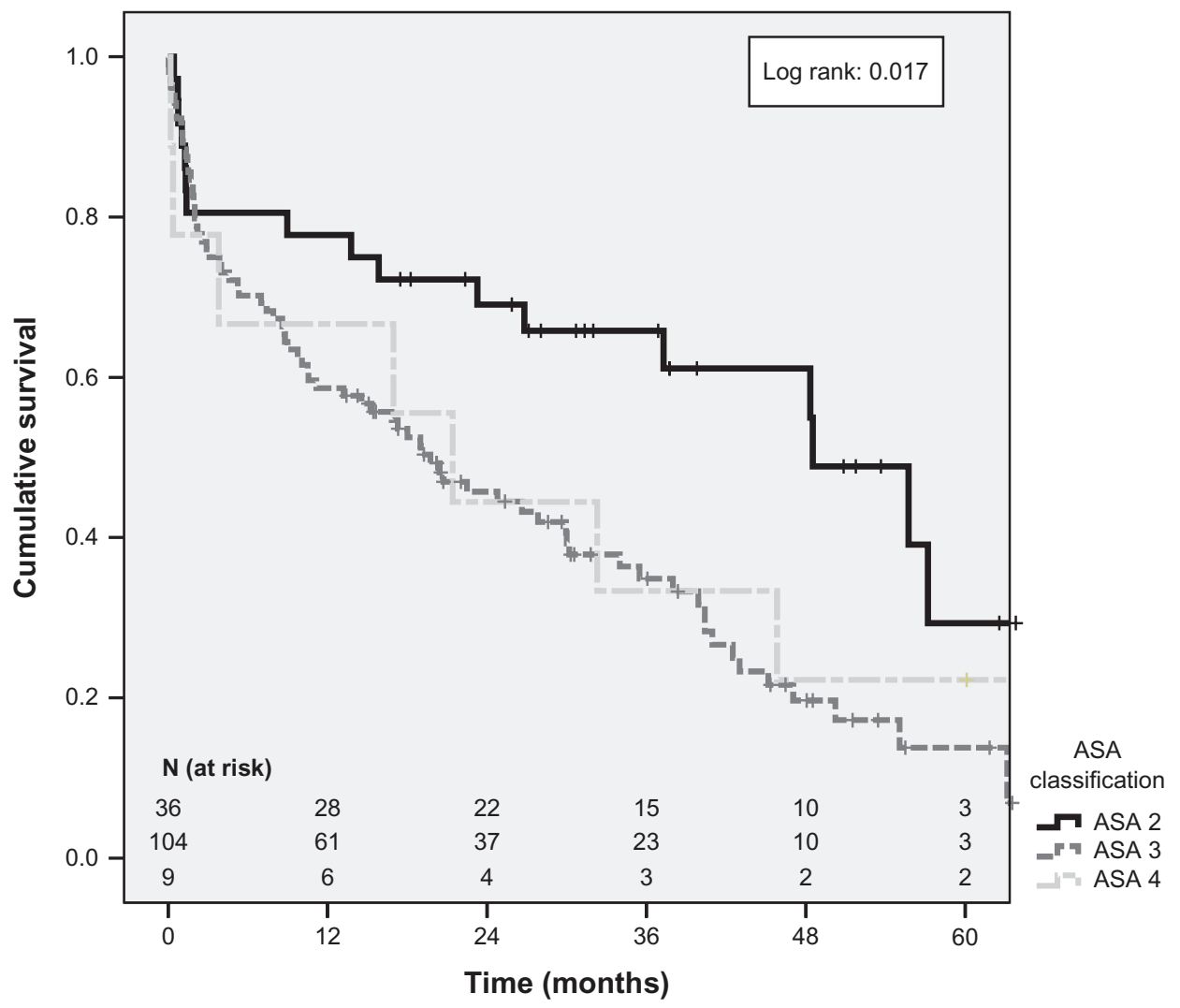

Figure 2 Survival according to ASA classification.

Abbreviation: ASA, American Society of Anesthesiologists. 


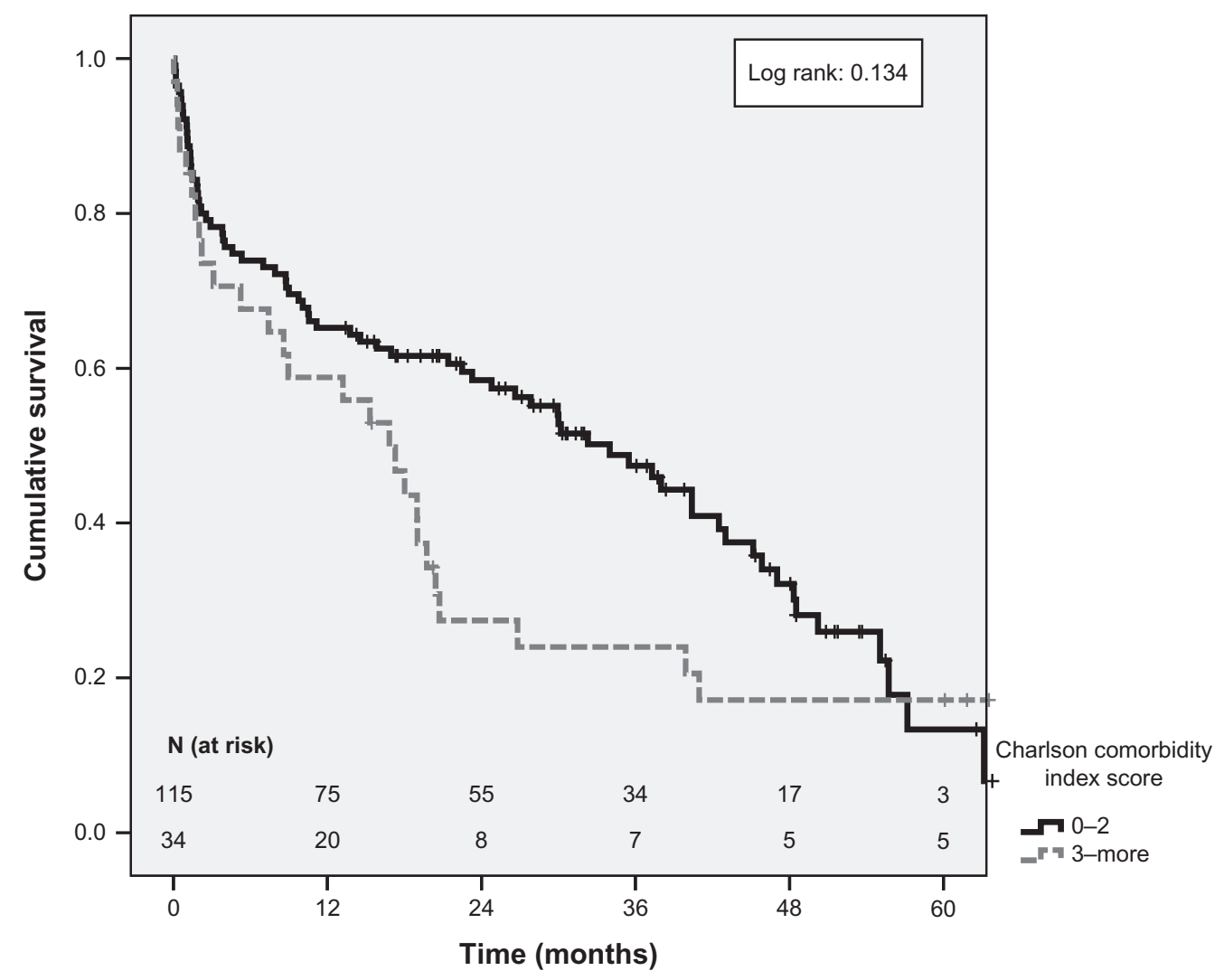

Figure 3 Survival according to Charlson comorbidity index score.

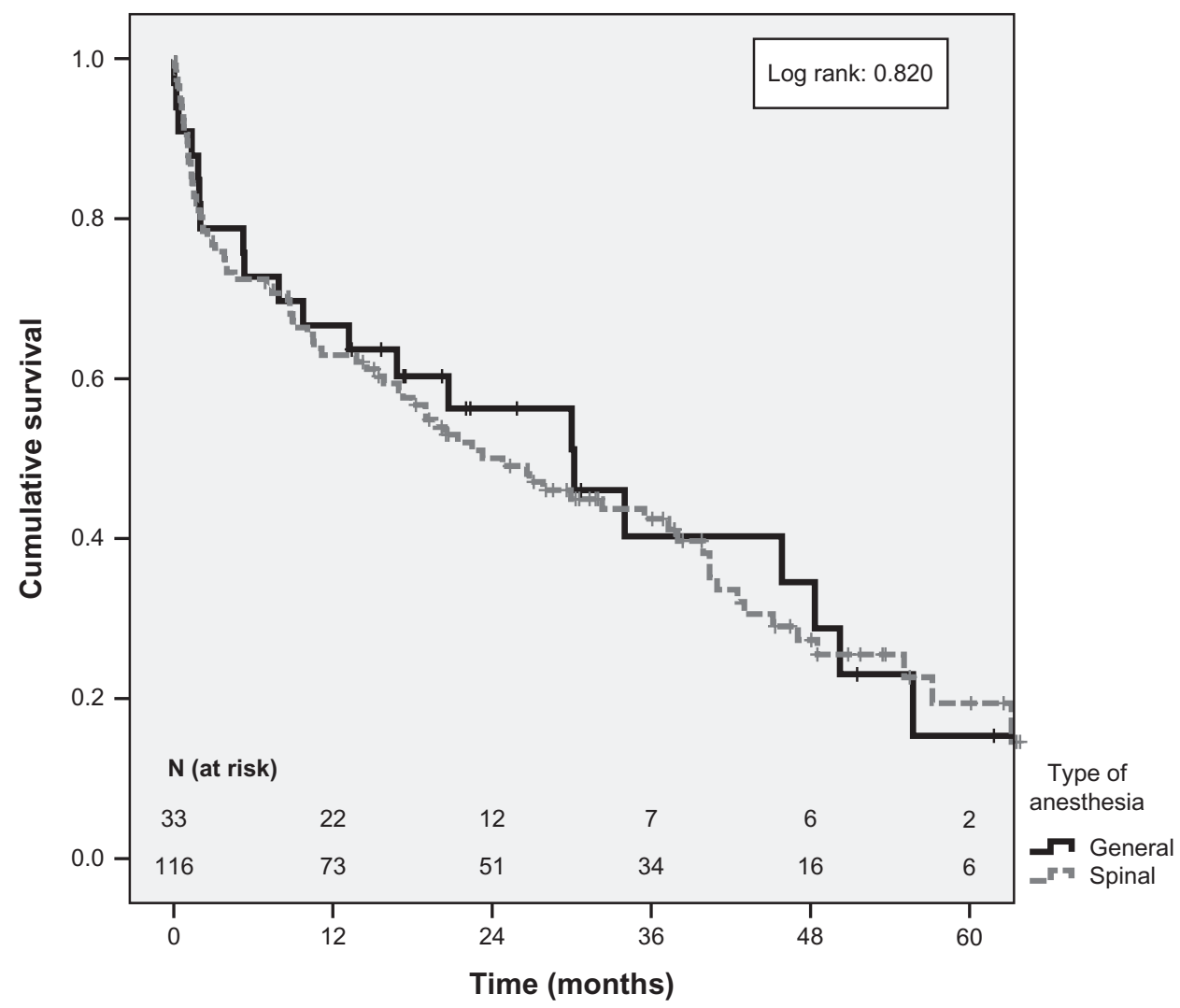

Figure 4 Survival according to type of anesthesia. 


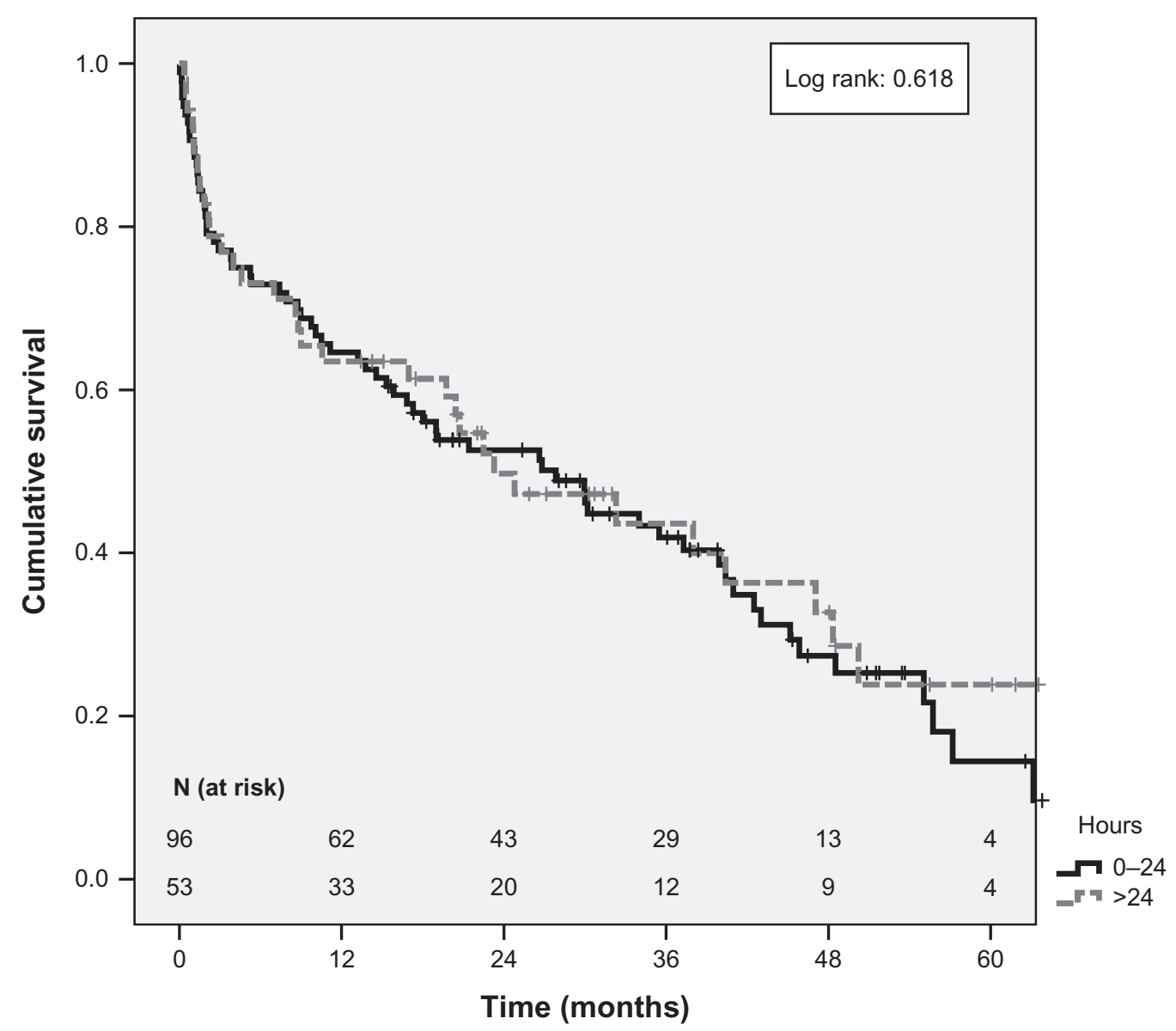

Figure 5 Survival according to time between occurrence of hip fracture and surgery.

To determine the predictive value of these different parameters on short-term mortality we measured mortality rates in only the first 3 months, during which 34 deaths were observed. Univariate analyses using the log-rank test showed that fully independent patients had a lower short-term mortality rate $(P=0.010)$ and that postoperative delirium was associated with a higher short-term mortality rate $(P=0.019)$. Entering all variables simultaneously, now also including the continuous variables of age and length of hospital stay, in the Cox proportional hazards model led to a significant effect on short-term mortality $(P=0.013)$. The significant variables were age $(P=0.013)$ and length of hospital stay $(P=0.030)$. A 1-year increase in age and a 1-day increase in length of hospital stay resulted in short-term mortality rate ratios of 1.19 (95\% CI: $1.04-1.37)$ and 1.03 (95\% CI: 1.00-1.06), respectively. Fully independent patients had a lower shortterm mortality $(P=0.052$; mortality rate ratio $=0.38 ; 95 \%$ CI: $0.14-1.01)$. The effect of postoperative delirium was no longer significant $(P=0.16)$ as it was confounded with length of hospital stay. $P$-values of the other variables in the model ranged from 0.46 to 0.98 .
Postoperative delirium was diagnosed in 49 (33\%) patients. Median length of hospital stay in patients with postoperative delirium was 13 days against 9 days in patients without delirium ( $P=0.049$ ).

Preoperatively, place of residence was the patient's own home or a sheltered accommodation in 66 patients; only $20(30 \%)$ of them returned to this place after surgery for hip fracture. The other 46 (70\%) patients were discharged to a nursing or care home. Out of 39 patients preoperatively living in a nursing home, $16(41 \%)$ returned to the nursing home after surgery and 23 (59\%) were discharged to a care home. All patients living in a care home preoperatively $(\mathrm{N}=31)$ were discharged to a care home after surgery. In summary, 69 of $136(51 \%)$ patients were discharged to a place with more care after undergoing osteosynthesis for a hip fracture (Table 3).

Regarding the consequences of a hip fracture on patient mobility we found the following results. Preoperative mobility was fully independent in 49 patients, but after surgery 44 (90\%) patients needed a walking aid/frame, four $(8 \%)$ patients ended up in a wheelchair, and only one 
Table 3 Place of residence before and after surgery for hip fracture

\begin{tabular}{lllll}
\hline & \multicolumn{3}{l}{ Postoperative } & \\
\cline { 2 - 3 } & $\begin{array}{l}\text { Own } \\
\text { home }\end{array}$ & Sheltered & $\begin{array}{l}\text { Nursing } \\
\text { home }\end{array}$ & $\begin{array}{l}\text { Care } \\
\text { home }\end{array}$ \\
\hline $\begin{array}{l}\text { Preoperative } \\
\text { Own home } \\
(n=54)\end{array}$ & $16(29.6 \%)$ & $3(5.6 \%)$ & $8(14.8 \%)$ & $27(50.0 \%)$ \\
$\begin{array}{l}\text { Sheltered } \\
(n=12)\end{array}$ & 0 & $1(8.3 \%)$ & $4(33.3 \%)$ & $7(58.3 \%)$ \\
$\begin{array}{l}\text { Nursing home } \\
(n=39)\end{array}$ & 0 & 0 & $16(41.0 \%)$ & $23(59.0 \%)$ \\
$\begin{array}{l}\text { Care home } \\
(n=31)\end{array}$ & 0 & 0 & 0 & $31(100.0 \%)$ \\
\hline
\end{tabular}

(2\%) patient managed to walk fully independently. Seventyfive patients used a walking aid/frame before their fracture. Postoperatively, 53 (71\%) of them were mobile with the same walking aid/frame, whereas the other 22 (29\%) patients ended up in a wheelchair. The three patients who were already in a wheelchair remained as such after surgery. Thus, 70 of 124 (57\%) patients were less mobile after undergoing osteosynthesis of a hip fracture (Table 4).

\section{Discussion}

To our knowledge, this is the first study to describe the functional outcome and short-term and long-term mortality after osteosynthesis of a hip fracture in a large population of patients aged over 90 years. With the progressive increase in life expectancy and population growth, the incidence of hip fractures will increase in the near future. ${ }^{20}$ Advanced age, male gender, previous hospitalization, comorbidity, and other factors are known to be associated with increased morbidity and mortality and poor functional results after hip fracture. ${ }^{6,20}$ Yet, there is still no clear objective method for predicting the outcome of surgery in very elderly patients with hip fractures.

Table 4 Patient's mobility before and after surgery for a hip fracture

\begin{tabular}{lllll}
\hline & \multicolumn{3}{l}{ Postoperative } & \\
\cline { 2 - 5 } & $\begin{array}{l}\text { No } \\
\text { aids }\end{array}$ & $\begin{array}{l}\text { One } \\
\text { aid }\end{array}$ & $\begin{array}{l}\text { Walking } \\
\text { frame }\end{array}$ & Wheelchair \\
\hline $\begin{array}{l}\text { Preoperative } \\
\text { No aids } \\
(n=49)\end{array}$ & I (2.0\%) & $3(6.1 \%)$ & 4 I (83.7\%) & $4(8.2 \%)$ \\
$\begin{array}{l}\text { One aid } \\
(n=6)\end{array}$ & 0 & 0 & $4(66.7 \%)$ & $2(33.3 \%)$ \\
$\begin{array}{l}\text { Walking frame } \\
(n=69)\end{array}$ & 0 & 0 & $49(71.0 \%)$ & $20(29.0 \%)$ \\
$\begin{array}{l}\text { Wheelchair } \\
(n=3)\end{array}$ & 0 & 0 & 0 & $3(100.0 \%)$ \\
\hline
\end{tabular}

ASA classification and the CCI are both scoring systems for preoperative comorbidity. Burgos et al reported a relation between $\mathrm{CCI}$ and the development of serious complications during hospital stay. ${ }^{20}$ In our study population with patients aged 90 years or older, mortality rates in patients with higher ASA scores were significantly higher in comparison to those with lower ASA scores. On the other hand, CCI was not found to be predictor for mortality. Earlier studies already described a nine-fold increased risk for mortality in patients with high ASA scores ( 3 or 4). ${ }^{20,21}$ Therefore, ASA classification also seems to be the best predictive indicator for overall mortality after osteosynthesis of hip fractures in extremely elderly patients.

Because of the relative short life expectancy of extremely elderly patients it is interesting to look at the predictive value of risk factors on short-term mortality. An earlier study described exceptionally high mortality rates in the first 3 months after hip fracture. ${ }^{22}$ Indeed, our study showed a mortality rate of $23 \%$ in the first 3 months after surgery. However, we could not find a clear relationship between CCI scores, ASA scores, type of anesthesia, or total preoperative delay and the 3-month mortality rate. Given the fact that the total preoperative delay also did not influence long-term mortality, this suggest that the patients' general condition can possibly be optimized before surgery. De Palma et al described similar results with a preoperative delay of 48 hours. ${ }^{23}$ They concluded that patients with comorbidity conditions requiring stabilization do not necessarily need to be treated within 48 hours.

Delirium is a common complication in elderly patients after hip fracture surgery and is associated with adverse outcomes, including longer length of hospital stay, greater rate of institutional placement, greater dependence on others, higher costs, delayed recovery, and increased mortality. ${ }^{24}$ In our study, length of hospital stay was significantly longer in patients with delirium. A longer length of stay was associated with higher short-term mortality, adjusted for delirium and other variables. Vochteloo et al described an integrated hip fracture care pathway that included a Risk Model for Delirium (RD) score. ${ }^{25}$ They concluded RD score was an accurate tool for identifying high-risk patients with poorer outcomes regarding delirium incidence, length of hospital stay, and return to pre-fracture living situation. ${ }^{25}$ Wagner et al found a small benefit of geriatric intervention in elderly patients operated on for a hip fracture, which was mainly demonstrated in improved and earlier detection of medical geriatric conditions such as anemia and delirium. ${ }^{26}$ Because of the poorer outcome measurements in patients with 
postoperative delirium, It remains important to diagnose and treat delirium at an early stage.

This study shows the loss of independence of extremely elderly persons after a hip fracture. Although many of these patients already have difficulties in walking and independent living, a large proportion of these patients are faced with a definitive loss of independence. ${ }^{5}$ More than half of the patients were discharged to a place with more care after undergoing osteosynthesis of a hip fracture and $57 \%$ of patients were less mobile after surgery. Fully independent patients had significantly lower mortality rates. Maybe in some cases, conservative treatment can be an alternative to surgery. However, this decision should be based on the individual patient and depends on several factors. Quality of life is an important factor in this decision and therefore it is recommended to study quality of life in further research.

\section{Conclusion}

As the general population is aging, an increasing number of extremely elderly patients will suffer from hip fractures. Our study shows that short-term mortality rates in these patients are high and there is no clear predictive value for mortality. ASA classification is the best predictive value for overall mortality in these patients. Finally, there is loss of independence in a large proportion of these patients after undergoing osteosynthesis of a hip fracture.

\section{Acknowledgments}

We wish to thank PGH Mulder for his valuable assistance with the statistical analysis. The authors received no financial support for the research, authorship, and/or publication of this article.

\section{Disclosure}

The authors report no conflicts of interest in this work.

\section{References}

1. Hartholt KA, van der Velde N, Looman CW, et al. Trends in fall-related hospital admissions in older persons in The Netherlands. Arch Intern Med. 2010;170(10):905-911.

2. van Staa TP, Dennison EM, Leufkens HG, Cooper C. Epidemiology of fractures in England and Wales. Bone. 2001;29(6):517-522.

3. Beaupre LA, Jones CA, Saunders LD, Johnston DW, Buckingham J, Majumdar SR. Best practices for elderly hip fracture patients. A systematic overview of the evidence. J Gen Intern Med. 2005;20(11): 1019-1025.

4. United Nations. United Nations World Population Prospects, The 2006 Revision. New York, NY: United Nations; 2007.
5. Holt G, Smith R, Duncan K, Hutchinson JD, Gregori A. Outcome after surgery for the treatment of hip fracture in the extremely elderly. $J$ Bone Joint Surg Am. 2008;90(9):1899-1905.

6. Holt G, Macdonald D, Fraser M, Reece AT. Outcome after surgery for fracture of the hip in patients aged over 95 years. J Bone Joint Surg Br. 2006;88(8):1060-1064.

7. Tarity TD, Smith EB, Dolan K, Rasouli MR, Maltenfort MG. Mortality in centenarians with hip fractures. Orthopedics. 2013;36(3):e282-e287.

8. Kannus P, Parkkari J, Koskinen S, et al. Fall-induced injuries and deaths among older adults. JAMA. 1999;281(20):1895-1899.

9. Hausdorff JM, Rios DA, Edelberg HK. Gait variability and fall risk in community-living older adults: a 1-year prospective study. Arch Phys Med Rehabil. 2001;82(8):1050-1056.

10. Tinetti ME, Williams CS. Falls, injuries due to falls, and the risk of admission to a nursing home. N Engl J Med. 1997;337(18):1279-1284.

11. Hartholt KA, van Beeck EF, Polinder S, et al. Societal consequences of falls in the older population: injuries, healthcare costs, and long-term reduced quality of life. J Trauma. 2011;71(3):748-753.

12. Consensus development conference: diagnosis, prophylaxis, and treatment of osteoporosis. Am J Med. 1993;94(6):646-650.

13. Black DM, Arden NK, Palermo L, Pearson J, Cummings SR. Prevalent vertebral deformities predict hip fractures and new vertebral deformities but not wrist fractures. Study of Osteoporotic Fractures Research Group. J Bone Miner Res. 1999;14(5):821-828.

14. Curran D, Maravic M, Kiefer P, Tochon V, Fardellone P. Epidemiology of osteoporosis-related fractures in France: A literature review. Joint Bone Spine. 2010;77(6):546-551.

15. Braithwaite RS, Col NF, Wong JB. Estimating hip fracture morbidity, mortality and costs. J Am Geriatr Soc. 2003;51(3):364-370.

16. Boonen S, Singer AJ. Osteoporosis management: impact of fracture type on cost and quality of life in patients at risk for fracture I. Curr Med Res Opin. 2008;24(6):1781-1788.

17. Chrischilles EA, Butler CD, Davis CS, Wallace RB. A model of lifetime osteoporosis impact. Arch Intern Med. 1991;151(10):2026-2032.

18. Charlson ME, Pompei P, Ales KL, MacKenzie CR. A new method of classifying prognostic comorbidity in longitudinal studies: development and validation. J Chronic Dis. 1987;40(5):373-383.

19. Owens WD, Felts JA, Spitznagel EL. ASA physical status classifications: a study of consistency ratings. Anesthesiology. 1978;49(4):239-243.

20. Burgos E, Gomez-Arnou JI, Diez R, Munoz L, FernandezGuisasola J, Garcia del Valle S. Predictive value of six risk scores for outcome after surgical repair of hip fracture in elderly patients. Acta Anaesthesiol Scand. 2008;52(1):125-131.

21. Paksima N, Koval KJ, Aharanoff G, et al. Predictors of mortality after hip fracture: a 10-year prospective study. Bull NYU Hosp Jt. 2008;66(2):111-117.

22. Diamantopoulos AP, Hoff M, Skoie IM, Hochberg M, Haugeberg G. Short- and long-term mortality in males and females with fragility hip fracture in Norway. A population-based study. Clin Interv Aging. 2013;8:817-823.

23. de Palma L, Torcianti M, Meco L, Catalani A, Marinelli M. Operative delay and mortality in elderly patients with hip fracture: an observational study. Eur J Orthop Surg Traumatol. 2013.

24. Lee KH, Ha YC, Lee YK, Kang H, Koo KH. Frequency, risk factors, and prognosis of prolonged delirium in elderly patients after hip fracture surgery. Clin Orthop Relat Res. 2011;469(9):2612-2620.

25. Vochteloo AJH, Moerman S, Borger van der Burg BLS, et al. Delirium risk screening and haloperidol prophylaxis program in hip fracture patients is a helpful tool in identifying high-risk patients, but does not reduce the incidence of delirium. BMC Geriatr. 2011;11:39.

26. Wagner P, Fuentes P, Diaz A, et al. Comparison of complications and length of hospital stay between orthopedic and orthogeriatric treatment in elderly patients with a hip fracture. Geriatr Orthop Surg Rehabil. 2012;3(2):55-58 
Clinical Interventions in Aging

\section{Publish your work in this journal}

Clinical Interventions in Aging is an international, peer-reviewed journal focusing on evidence-based reports on the value or lack thereof of treatments intended to prevent or delay the onset of maladaptive correlates of aging in human beings. This journal is indexed on PubMed Central, MedLine, the American Chemical Society's 'Chemical Abstracts

Service' (CAS), Scopus and the Elsevier Bibliographic databases. The manuscript management system is completely online and includes a very quick and fair peer-review system, which is all easy to use. Visit $\mathrm{http}: / / \mathrm{www}$.dovepress.com/testimonials.php to read real quotes from published authors.

Submit your manuscript here: http://www.dovepress.com/clinical-interventions-in-aging-journal 